\title{
PENELITIAN PENENTUAN KONSTANTA SATURASI (Ks) PADA RBC UNIT
}

Oleh : Prayitno.

\section{ABSTRACT}

Kinetic of Rotating Biological Contactor have been investigated by many researchers. In general the model employed either saturation kinetic (following Monod equation) or first order kinetic to describe substrate removal. In this experiment, saturation kinetic model was used to find out the saturation constant of the $\mathrm{RBC}$ unit. The influent fed into the unit was synthetic waste water with glucose as organic carbon sources. The flow was maintained constant at $20.4 \mathrm{l} / \mathrm{d}$ and COD influent was in range of 414.05 to $644.92 \mathrm{mg} /$. Analysis data by using last square method resulted the saturation constant (Ks) $11.17 \mathrm{mg} / 1$ with 20 hours of detention time.

\section{PENDAHULUAN}

Rotating Biological Contactor (RBC) adalah suatu sistem penanganan limbah secara biologi, dimana biomas aktif lebih banyak yang menempel dalam suatu plat bentuk lingkaran dari pada yang tersuspensi dalam larutan seperti dalam sitem lumpur aktip. Beberapa keuntungan dengan mengunakan $\mathrm{RBC}$ antara lain:

- Detention time (waktu menetap) yang pendek karena luas permukaan yang kontak dengan cairan limbah lebih besar.

- Mempunyai kemampuan untuk menangani limbah dengan kualitas limbah yang bervariasi tanpa mengalami shock loading.

- Tidak memerlukan tempat yang luas.

- Tidak diperlukan recycle sludge.

- Biomas lepas mudah diendapkan. 
Untuk mendesain suatu RBC unit perlu terlebih dulu dicari konstanta saturasi (Ks) dari sistem tersebut.

Konstanta saturasi (Ks) adalah kadar dari substrat (organik carbon) yang mana akan memberikan kecepatan pertumbuhan biomas $(\mu)$ separo dari kecepatan pertumbuhan maksimum $\left(\mu_{\max }\right)$. Untuk mencari Ks, Benefield (1985) telah mengembangkan Monod model dengan didasarkan pada kesetimbangan material.

$\Sigma\left|\begin{array}{l}\text { Perubahan konsentrasi } \\ \text { substrat dalam reaktor }\end{array}\right|=\Sigma\left|\begin{array}{l}\text { Konsentrasi substrat } \\ \text { masuk reaktor }\end{array}\right|-\Sigma\left|\begin{array}{l}\text { Konsentrasi } \\ \text { substrat yang } \\ \text { hilang dalam } \\ \text { reaktor. }\end{array}\right|$

Dengan menggunakan persamaan matematika, maka kesetimbangan material dapat dituliskan sebagai berikut:

$$
\frac{d s}{d t} V^{2}=Q_{o}-\left(\frac{d s}{d t}\right)_{u A} V_{c}+\left(\frac{d s}{d t}\right)_{u s} V_{s}+Q S_{e}
$$

Dimana:

ds

- $=$ perubahan konsentrasi substrat $(\mathrm{mg} / \mathrm{/} / \mathrm{d})$

dt

$\mathrm{V} \quad=$ Volume reaktor $(\mathrm{l})$

$\mathrm{Q} \quad=$ debit influent $(\mathrm{L} / \mathrm{d})$

$\mathrm{S}_{0} \quad=$ konsentrasi substrat influent $(\mathrm{mg} / \mathrm{l})$

$\mathrm{S} \quad=$ konsentrasi substrat effluent $(\mathrm{mg} / \mathrm{l})$

$\mathrm{v}^{\mathrm{e}} \quad=$ volume biomas aktif yang melekat pada disk(l)

$\mathrm{v}_{\mathrm{s}} \quad=$ volume biomas dalam larutan ( $\left.\mathrm{l}\right)$

$\left(\frac{\mathrm{ds}}{\mathrm{d}}\right)=$ kecepatan penggunaan substrat per unit volume oleh

$\left(\frac{\mathrm{dt}}{\mathrm{dt}}\right.$ biomas yang melekat dalam disk, $\mathrm{mg} / \mathrm{l} / \mathrm{d}$.

$\left(\frac{d s}{d t}\right)^{u A}=$ kecepatan penggunaan substrat per unit volume oleh is biomas tersuspensi, $\mathrm{mg} / \mathrm{/} / \mathrm{d}$.

Bila energi yang digunakan untuk pemeliharaan pertumbuhan biomas diabaikan, maka persamaan (1) menjadi :

$$
\frac{\mathrm{ds}}{\mathrm{dt}} \mathrm{V}=\mathrm{QS}_{0}-\left(\frac{\mu_{\mathrm{A}} \mathrm{X}_{\mathrm{f}}}{\mathrm{Y}_{\mathrm{A}}}\right)_{\mathrm{uA}} \mathrm{V}_{\mathrm{a}}+\left(\frac{\mu_{\mathrm{s}} \mathrm{X}_{\mathrm{f}}}{\mathrm{Y}_{\mathrm{S}}}\right)_{\mathrm{US}} \mathrm{V}_{\mathrm{s}}+\mathrm{QS}_{\mathrm{e}}
$$

\section{Dimana:}

$\mathrm{X}_{\mathrm{f}}=$ biomas aktif per unit volume dari biomas yang melekat pada disk $(\mathrm{mg} / \mathrm{l})$
$\mathrm{X},=$ biomas aktif per unit volume dari biomas tersuspensi (mg/)

$\mathrm{Y}^{*}=$ kecepatan tumbuh spesifik dari biomas yang melekat dalam disk $\mathrm{d}^{-1}$

$\mathrm{Y}^{*},=$ kecepatan tumbuh spesifik dari biomas tersuspensi $\left(\mathrm{d}^{-1}\right)$

$\mu_{\mathrm{a}}=$ kecepatan tumbuh biomas dalam disk $(\mathrm{mg} / \mathrm{l} / \mathrm{d})$

$\mu_{s}=$ kecepatan tumbuh biomas tersuspensi ( $\left.\mathrm{mg} / \mathrm{l} / \mathrm{d}\right)$

Apabila $\mathrm{d}=$ tebal dari biomas aktif dalam disk sedangkan $\mathrm{A}=$ luas disk yang terendam dalam larutan limbah yang mana :

$$
A=2 N \pi\left(r_{o}^{2}-r_{u}^{2}\right)
$$

$\begin{array}{ll}\text { Dengan } & \mathrm{N}=\text { jumlah disk } \\ & \mathrm{r}=\text { jari-jari disk }\end{array}$

$\mathrm{r}_{\mathrm{o}} \quad=$ jari-jari disk total,dm

$\mathrm{r}_{\mathrm{u}} \quad=$ jari-jari disk yang tak teredam larutan, $\mathrm{dm}$

Dengan memasukan persamaan (3) kedalam (2) dan dalam keadaan setimbang maka persamaan menjadi:

$$
\mathrm{O}=\mathrm{QSo}-\left(\frac{\mu_{\mathrm{A}} \mathrm{X}_{\mathrm{f}}}{\mathrm{Y}_{\mathrm{A}}}\right) \mathrm{uAd} 2 \mathrm{~N} \pi\left(\mathrm{r}_{\mathrm{o}}{ }^{2}-\mathrm{r}_{\mathrm{u}}{ }^{2}\right)+\left(\frac{\mu \mathrm{XXf}}{\mathrm{Y}_{S}}\right)_{u S} \mathrm{~V}_{\mathrm{s}}+\mathrm{QS}_{\mathrm{e}}
$$

Pertumbuhan biomas mengikuti persamaan Monod:

$$
\begin{aligned}
& \mu=\mu_{\max } \times \frac{S_{0}}{K_{s}+S} \\
& \text { andaikan } \quad p=\frac{\left(\mu_{\operatorname{mak}}\right)_{A} X_{f} d}{Y_{A}}
\end{aligned}
$$

dengan mensubstitusikan persamaan (5) dan (6) ke (4) akan diperoleh persamaan linier :

$$
\frac{2 N \pi\left(r_{0}^{2}-r_{u}^{2}\right)}{Q\left(S_{0}-S_{e}\right)}=\frac{K_{s}}{p S_{c}}+\frac{1}{p}
$$

Sesuai dengan persamaan garis linier $\mathrm{Y}=\mathrm{aX}+\mathrm{B}$ didapat :

$$
Y=\frac{2 N \pi\left(r_{0}^{2}-r_{u}^{2}\right)}{Q\left(S_{o}-S_{e}\right)}
$$


$X=\frac{1}{S_{e}}$

\section{MATERI DAN METODA PENELITIAN}

Materi Penelitian

1. Bahan

Bahan baku yang digunakan dalam penelitian ini meliputi

a. Bahan untuk limbah cair sintetis dengan komposisi :

\begin{tabular}{|lc|}
\hline Bahan kimia & Jumlah per liter $(\mathrm{g})$ \\
\hline Glucose & 60 \\
Urea & 5 \\
$\mathrm{~K}_{2} \mathrm{HPO}_{4}$ & 0,85 \\
$\mathrm{KH}_{2} \mathrm{PO}_{4}$ & 2,18 \\
$\mathrm{Na}_{2} \mathrm{HPO}_{2}$ & 1,77 \\
$\mathrm{NH}_{4} \mathrm{Cl}$ & 0,17 \\
$\mathrm{MgSO}_{4} \cdot 7 \mathrm{H}_{2} \mathrm{O}$ & 2,25 \\
$\mathrm{CaCl}_{2}$ & 2,75 \\
$\mathrm{FeCl}_{3} \cdot 6 \mathrm{H}_{2} \mathrm{O}$ & 0,03 \\
\hline
\end{tabular}

b. Bahan kimia untuk pengujian COD

\section{Peralatan}

a. $\mathrm{RBC}$ unit reaktor.

b. Alat-alat gelas untuk pengujian $\mathrm{COD}$.
1. Skema reaktor untuk penelitian

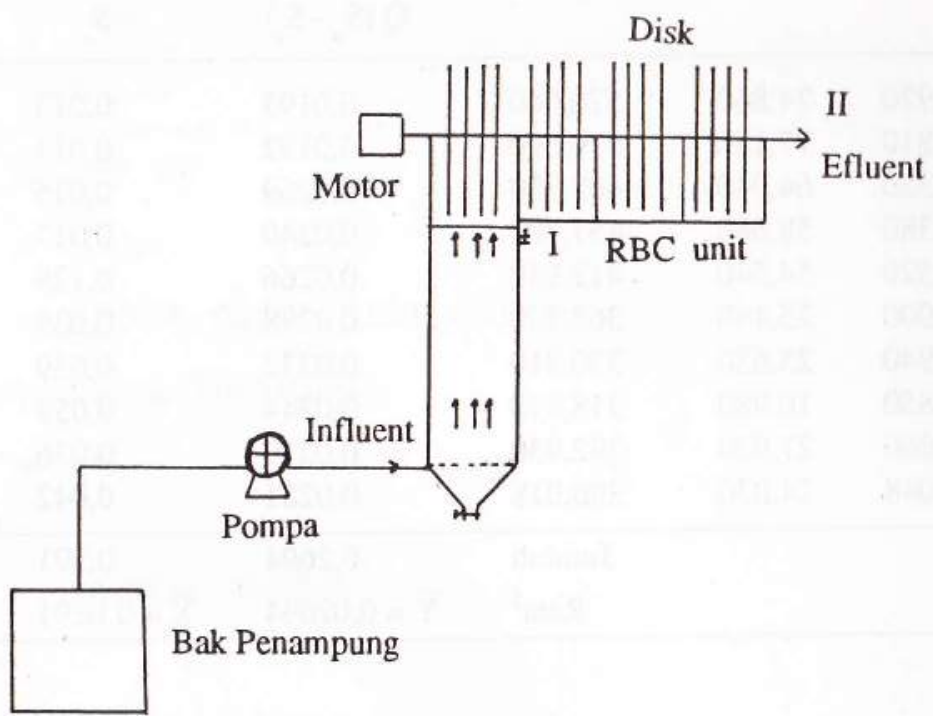

\section{Cara kerja.}

Limbah cair sintetik dalam bak penampungan dipompa menggunakan pompa peristaltik dengan kecepatan 20,4 l/d masuk melalui kolom gelas kemudian masuk ke unit RBC dengan waktu menetap 20 jam. COD diukur pada titik sampling I dan II.

\section{Metoda analisa data.}

Dengan last square method, data-data COD yang diperoleh di plotkan pada persamaan (7) dengan $N=16, r_{0}=1,5 \mathrm{dm}, r_{u}=0,15 \mathrm{dm}$ dan $\mathrm{Q}=20,41 / \mathrm{d}$.

\section{HASIL PENELITIAN DAN PEMBAHASAN}

\section{A. Hasil Penelitian.}

Dari percobaan dilakukan pengujian terhadap COD influent ( $S$ ) dan COD effluent $\left(\mathrm{S}_{\mathrm{e}}\right)$. Data-data hasil analisa $\mathrm{COD}$ yang didapat kemudian dilakukan analisa data sebagai berikut : 


\section{DAFTAR PUSTAKA}

1. Benefield. L.D., Randal, C.W., 1980, Biologigal Process Design for Wastewater Treatment, Prentice-Hall, Inc., Engleppwood Cliffs, New Jersey, USA.

2. Clark, J.H., Moseng, E.M., 1978, Performance of Metal Removal ppwith Rotating Biological Contactor Under Varying Wastewater Flow, Journal WPCF, vol 50, No. 5, pp901-911.

3. Kornegay, B.H., Andrews, J.W., 1968, Kinetic of Fixed Film Biological Contactor, Journal WPCF, vol 40, pp460-468.

4. Pano, A.L., Reynolds, D.H., 1980, The Kinetic of Rotating Biological Contactor Treating Domestic Sewage, Proceeding First National Symposium/Workshop on Rotating Biological Contactor Technology, Pensylvania vol II, pp 449-467. 